\title{
'What's love got to do with it?' Ethics, emotions, and encounter in International Relations ${ }^{1}$
}

\author{
Véronique Pin-Fat ${ }^{*}$ \\ University of Manchester \\ ${ }^{\star}$ Corresponding author. Email: veronique.pin-fat@manchester.ac.uk
}

(Received 5 January 2018; revised 7 August 2018; accepted 21 September 2018; first published online 15 November 2018)

\begin{abstract}
By paying attention to love, this article offers a grammatical reading of International Relations' founding grammar of inside/outside as an ethics of encounter. The decision to focus on love is, I suggest, to contend with the possibility that IR may express a lethal politics and ethics. I seek to substantiate this claim through an unsettling reading of neo-Jamesian contributions to the emotional turn. I conclude that the discipline's founding grammar is an 'avoidance of love' and offer a reminder that an alternative way of loving is possible.
\end{abstract}

Keywords: Emotional Turn; Emotions; Grammatical Reading; Love; Ethics; Stanley Cavell; Ludwig Wittgenstein

\section{Introduction}

By paying attention to love, this article offers a re-reading of International Relations (IR)'s founding grammar of inside/outside as an ethics of encounter. ${ }^{2}$ It does so by providing the first grammatical reading of emotions in the discipline to confront the 'central challenge [of] ... their ethical implications. ${ }^{3}$ The decision to focus on love is, I suggest, to contend with the possibility that IR expresses a politics and ethics that is 'a lethal set of attempts to deny the existence of the other as essential to one's own'. ${ }^{4}$ Put simply, a grammatical reading reveals an avoidance of love to be a founding feature of IR that is hidden in plain sight. ${ }^{5}$

Any detailed example of how IR is an avoidance of love is rendered visible through a grammatical reading of the recent 'emotional turn' - the very place one might expect to be most hospitable to including love and perhaps, the least likely to be haunted by boundaries that distinguish a sovereign inside from outside. However, I seek to show that even here, IR's founding grammar of inside/outside continues to seduce our political and moral imaginary with lethal effects.

Emotions present a problem for IR. A widely accepted articulation is that 'the key challenge in emotions research: '[is] to understand how individual emotions can become collective and

\footnotetext{
${ }^{1}$ Song title: Tina Turner, Graham Lyle, and Terry Britten, 'What's Love Got to Do with It?' (Capitol, 1984).

${ }^{2}$ R. B. J. Walker's seminal work first brought the captivating influence of this grammar to IR's attention. R. B. J. Walker, Inside/Outside: International Relations as Political Theory (Cambridge: Cambridge University Press, 1993).

${ }^{3}$ Emma Hutchison and Roland Bleiker, 'Theorizing emotions in world politics', International Theory, 6:3 (2014), pp. 491-514 (p. 494).

${ }^{4}$ Stanley Cavell, Philosophy the Day after Tomorrow (Cambridge, MA: Belknap Press of Harvard University Press, 2005 ), p. 12.

${ }^{5}$ For a 'sociology of the invisible' that presents IR as a 'failure to love' feminist scholarship, see Raluca Soreanu and David Hudson, 'Feminist scholarship in International Relations and the politics of disciplinary emotion', Millennium: Journal of International Studies, 37:1 (2008), pp. 123-51. The article brilliantly maps out an emotional landscape (rather than, as here, the grammatical constitution) of IR's disciplinary disavowal of love.
}

(c) British International Studies Association 2018. 
political'. ${ }^{6}$ Apparently, the epistemological task is to bridge the ontological gap between the individual and the collective by 'grappling with how to adequately conceptualize and capture the collective significance of phenomena that seem more private than public, inchoate than concrete, and susceptible to the scrutiny of social science. ${ }^{7}$. To understand the problem this way is to accept an inside/outside grammar of scepticism in two ways. Firstly, as the possibility of doubting whether the other has emotions, feelings, or an inner life for lack of direct access to those (private, inner, hidden) experiences. And consequently, secondly, it privileges knowledge as a mode of encounter with the other. This is because only knowledge can successfully cross the threshold of epistemological doubt such that collective emotions might properly be 'susceptible to the scrutiny of [IR as a] social science'. ${ }^{8}$

To take ethics as central to IR and the emotional turn requires considering not only what IR theorises but, vitally, how it theorises. Accordingly, the grammatical reading offered here seeks to make explicit the implicit ethics of theorising emotions in ways that are produced by scepticism. As we shall see, in IR's emotional turn, neo-Jamesian language games of emotion paradigmatically assume and express the grammar of the 'skeptical recital' and its demand for knowledge in a register the sovereign can recognise. For Stanley Cavell, the sceptical recital produces a violent politics and ethics of encounter that denies relationality and with it, avoids love. Pursuing a grammatical reading therefore, is an attempt to reveal this. It is an attempt to render the familiar unfamiliar. ${ }^{10}$ Rather than answering ontological questions - 'What are emotions in IR?' - a grammatical reading stays on the surface of language and looks to what regulates ethical possibility and impossibility. ${ }^{11}$ Accepting that grammar controls what is possible in the world by regulating what kinds of statements one can make about 'reality', it is grammar (not the essence/nature of an object) that tells us what kind of 'object', like an emotion, is. Understood this way, specific grammars of specific language games express how 'objects' and more importantly, how people (including who counts as 'people') are understood to be in relation to and with each other. ${ }^{12}$ It is in this grammatico-political sense then, that I seek to represent IR as the avoidance of love using neo-Jamesianism as an example of the sceptical grammar that produces it.

My argument proceeds in the following way. First, I establish the presence of a sceptical grammar of inside/outside in IR's emotional turn. The claim is that IR's founding grammar of inside/outside is a paradigmatic feature of neo-Jamesian contributions to it. ${ }^{13}$ Second, I discuss Cavell's example of how the same grammar is an avoidance of love. The avoidance of love as an

\footnotetext{
${ }^{6}$ Hutchison and Bleiker, 'Theorizing emotions in world politics', p. 507.

${ }^{7}$ Emma Hutchison, 'A global politics of pity? Disaster imagery and the emotional construction of solidarity after the 2004 Asian Tsunami’, International Political Sociology, 8:1 (2014), pp. 1-19 (p. 3), emphasis added.

${ }^{8}$ Ibid., p. 3.

${ }^{9}$ This phrase is Cavell's and is a short way of referring to scepticism and attempts to refute it.

${ }^{10}$ Véronique Pin-Fat, Universality, Ethics and International Relations: A Grammatical Reading (Abingdon: Routledge, 2010).

${ }^{11}$ Ibid. Also, Véronique Pin-Fat, 'Cosmopolitanism and the end of humanity: a grammatical reading of posthumanism', International Political Sociology, 7:3 (2013), pp. 241-57; Véronique Pin-Fat, 'Cosmopolitanism without foundations', in Sonika Gupta and Sudarsan Padmanabhan (eds), Politics and Cosmopolitanism in a Global Age (New Delhi and London: Routledge, 2015); Véronique Pin-Fat, 'Seeing humanity anew: Grammatically reading liberal cosmopolitanism', in Tamara Caraus and Elena Paris (eds), Re-Grounding Cosmopolitanism: Towards a Post-Foundational Cosmopolitanism (Abingdon: Routledge, 2016).

${ }^{12}$ Pin-Fat, Universality, Ethics and International Relations, pp. 4-30.

${ }^{13}$ The emotional turn in IR is significantly broader than its neo-Jamesian contributions. See, for example, the important collection by Linda Åhäll and Thomas Gregory (eds), Emotions, Politics and War (London and New York: Routledge, 2015). Neo-Jamesianism is only one of the language games in the emotional turn but is important not only: (a) for its influence in setting some of its parameters but more importantly; (b) for being a paradigmatic articulation of IR's founding and dominant grammar of inside/outside. Henceforth, my use of the term 'the emotional turn' in IR refers specifically to neo-Jamesianism and my critique is not generalisable to the emotional turn writ large. Grammatical readings are an explicit ethico-political refusal to be seduced by the urge to generalise and/or universalise.
} 
emotion, tells us something important about an ethics of encounter as 'a lethal set of attempts to deny the existence of the other as essential to one's own'. ${ }^{14}$ Third, for the first time in IR, Cavell's reading of King Lear is used to articulate the sovereign demand for knowledge in an epistemological register that it can recognise. Cavell's great contribution to ordinary language philosophy has been his relentless focus on the ethical implications of the privileging of knowledge in philosophy. In a similar vein I suggest, fourth, that the presence of International Relations' disciplinary focus on knowledge, as the expression of an ethics of encounter, is best revealed grammatically. I show that neo-Jamesians' acceptance of the sovereign demand to know is evidenced by their understanding of emotions as a problem of knowledge. Accordingly, they respond in a register that the sovereign can recognise, which consists of providing evidence and proof of the existence of collective emotions. These responses to the sovereign demand to know take the form of solutions that act as a bridge for crossing the sceptic's threshold of knowability. Because, analogously, these solutions to the problem of knowing emotions in IR express the same grammar as King Lear, they too can be read as the avoidance of love. Finally, I conclude by outlining the ethical implications of the avoidance of love in IR's emotional turn and suggest that we consider responding to the demand to encounter the other through a knowledge relation the way Cordelia does; by refusing it and loving the other anyhow.

\section{Grammar, neo-Jamesianism, and the emotional turn in IR}

IR's emotional turn, while not wholly seduced by it, is very much influenced by research advances in psychology and neuroscience. And, it should be said, IR is not alone in its fascination with current research emerging from the field. Those philosophers of the emotions that are engaged with their findings are often labelled neo-Jamesians; scholars 'who advance a contemporary variant of William James's account of emotion' wherein emotions are explained 'in terms of bodily changes, usually patterned changes in the Autonomic Nervous System (ANS)' ${ }^{15}$ In this language game, what counts as an emotion are 'the bodily changes that follow directly the PERCEPTION of the exciting fact, and ... our feeling of the same changes as they occur'. ${ }^{16}$ An (individual) emotion refers to changes in the body and brain.

Neo-Jamesianism is a commitment to gaining knowledge of the emotions by identifying the objects - phenomena - to which they refer (naming). This assumes a picture theory of meaning wherein the meaning of words is derived from the objects that they name. ${ }^{17}$ Names 'picture', or represent, features of reality. In the case of emotions, the search is for strange, inner objects. At its strongest, a neo-Jamesian foundational claim is that 'any empirically supportable work finds that emotions emerge from, and exist within, the realm of the physical body, not least in the architecture of the human brain'. ${ }^{18}$ Supposedly, to posit the foundations of knowledge of emotional experience otherwise would be either 'hard to imagine' or worse, it would 'posit an ethereal existence, which enters the realm of the spiritual'. ${ }^{19}$

While not all views that turn to understanding emotions by focusing on how brains and bodies function are as exclusively materialist as this, in International Relations Neta Crawford and Jonathan Mercer are among the best-known scholars to have introduced a

\footnotetext{
${ }^{14}$ Cavell, Philosophy the Day after Tomorrow, p. 12.

${ }^{15}$ Phil Hutchinson, 'Emotion-philosophy-science', in Ylva Gustafsson, Camilla Kronqvist, and Michael McEachrane (eds), Emotions and Understanding: Wittgensteinian Perspectives (Palgrave Macmillan, 2009), p. 60.

${ }^{16}$ William James, 'II. - What is an emotion?', Mind (1884), pp. 188-205 (pp. 189-90), emphasis in original.

${ }^{17}$ Pin-Fat, Universality, Ethics and International Relations, p. 8.

${ }^{18}$ Rose McDermott, 'The body doesn't lie: a somatic approach to the study of emotions in world politics', International Theory, 6:3 (2014), pp. 557-62 (p. 562).

${ }^{19}$ Ibid., p. 562.
} 
neo-Jamesian approach to understanding emotions. ${ }^{20}$ Crawford's recent account of fear is typical. ${ }^{21}$ Fear names 'a cascade of reactions and consequences in the brain and the rest of the body. ${ }^{22}$ The possible routes of signals through the brain's amygdala, thalamus, or prefrontal cortex are mapped and offered as the cause, under certain conditions, for the production of 'a cascade of other biochemical events' that eventually culminate as bodily sensations (affect) affecting heart rate, breathing, and indigestion. ${ }^{23}$ Thus, the meaning of the word 'fear' refers to the 'object' of signals travelling through the brain, producing 'neurochemical messages' and the 'neurotransmitters' affecting the relevant glands producing hormones such as adrenaline and cortisol that give us the feeling of fear. ${ }^{24}$ As William James put it in 1884, 'our feeling of the ... [neurobiological] changes as they occur IS the emotion'. ${ }^{25}$

Jonathan Mercer also expresses an embodied, individual understanding of emotions. Mercer's explanation of emotions is similarly informed by the object to which the word refers. He also explicitly endorses William James's position by saying that 'Modern psychology and neurobiology support his central ideas. ${ }^{26}$ In this language game, an emotion like aggression should be understood as one where ' $\left[\mathrm{t}\right.$ ] he body produces these feelings, not cognition. ${ }^{27}$ Indeed, citing the research of the neo-Jamesian Antonio Damasio, ${ }^{28}$ Mercer defends the 'smoking gun' empirical evidence that demonstrates that cognition/rationality depends on emotion. ${ }^{29}$ In sum, what matters for our grammatical reading is that an emotion is defined 'as a subjective experience of some diffuse physiological change. ${ }^{30}$

In this picture, emotions are empirically embodied and because of this are necessarily, by definition, experienced exclusively in the body in which they arise, that is, 'inside,' individually, and privately. Or, as Mercer would put it, emotion 'has a first person, subjective ontology' that is biologically caused. ${ }^{31}$ The picture is one wherein emotional sensations belong to the individual and only she experiences them directly, even if the various hormones, neurotransmitters, etc. can be scientifically observed.

Further complicating such emotional objects is the observation that emotions, such as fear, can be remarkably fleeting. They can come upon us rapidly upon perceiving a threat and dissipate on the threat no longer being present. This aspect of the experience of emotions produces a sense that they are not only private but 'seem ephemeral and deeply internal ... and it

\footnotetext{
${ }^{20}$ Bleiker and Hutchison classify Crawford as a 'constructivist' emphasising her attention to 'particular historical, political and cultural contexts' when explaining how emotions transcend the individual and become 'political' in Roland Bleiker and Emma Hutchison, 'Fear no more: Emotions and world politics', Review of International Studies, 34:1 (2008), pp. 115-35 (p. 122). My grammatical reading of Crawford's stance differs because of its emphasis on her acceptance of a word-object relation as the bearer of meaning. Crawford does not consider 'biochemical events' and the variety of cascading 'reactions and consequences in the brain and body' to be socially constructed. In other words, the strange object to which a word like 'fear' refers is given. It is not constructed. However, the institutionalisation of emotions like fear is constructed. In fairness, her earlier work was more 'agnostic' about neo-Jamesian claims. See Neta C. Crawford, 'The passion of world politics: Propositions on emotion and emotional relationships', International Security, 24:4 (2000), pp. 116-56 (p. 125).

${ }^{21}$ As is her account of the neurobiological processes at work in empathy. See Neta C. Crawford, 'Institutionalizing passion in world politics: Fear and empathy', International Theory, 6:3 (2014), pp. 535-57.

${ }^{22}$ Ibid., p. 539.

${ }^{23}$ Ibid.

${ }^{24}$ Ibid.

${ }^{25}$ James, 'II. - What is an emotion?', p. 190.

${ }^{26} J o n a t h a n$ Mercer, 'Emotional beliefs', International Organization, 64:1 (2010), pp. 1-31 (p. 4).

${ }^{27}$ Ibid., p. 5.

${ }^{28}$ Antonio R. Damasio, Descartes' Error: Emotion, Reason, and the Human Brain (London: Macmillan, 1994).

${ }^{29}$ Mercer, 'Emotional beliefs', p. 9.

${ }^{30}$ It is important to note that he distinguishes this from a 'feeling', which he defines as 'a conscious awareness that one is experiencing an emotion'. Jonathan Mercer, 'Feeling like a state: Social emotion and identity', International Theory, 6:3 (2014), pp. 515-35 (p. 516).

${ }^{31}$ Ibid., p. 518.
} 
may be difficult to distinguish "genuine" emotions from their instrumental display'. ${ }^{32}$ In this picture, even if emotions refer to inner states, the occasion for scepticism arises. How can one distinguish between " genuine" emotions' and 'their instrumental display'? Part of the profoundly subjective aspect of emotion is 'the experience' of it and not just its biological causes. ${ }^{33}$ As Mercer says, 'Even if scientists conclude that someone should be in pain, the pain does not exist if it is not experienced. ${ }^{34}$ In other words, the only person who can have full and definitive access to knowledge of the emotion is the person experiencing it themselves. This is a classical articulation of a grammar of emotions that produces scepticism; how is it possible to know that others have feelings (a 'real' inner life) when only the person who has the experience can know? And, of course, if the privacy of emotions produces a knowledge gap between persons, then it is all the more acute when, in IR, researchers are seeking to understand how individual emotions can become collective and political'. ${ }^{35}$ This is otherwise known as philosophical scepticism of other minds and expresses a desire for knowledge.

Were one not yet convinced of the presence of a grammar of inside/outside and the scepticism of other minds that it generates, its nemesis - a machine that has feelings - makes its obligatory appearance. Indeed, it is claimed that if it were not for our inner lives then we would 'in principle' be able to build a machine that had feelings. To argue this way, of course, is an insistence that there is 'something' highly subjective about being human as opposed to a machine and that this 'something' has to do with the impossibility of an other having access to our 'experience'. Being unable to distinguish human beings from those who are, in fact, automatons is the sceptics' fear; the very thing that our desire to cross the threshold of knowability is meant to protect us from. If an automaton is sufficiently well programmed it may be able to act as though it has thoughts and emotions. ${ }^{36}$ It may even say, 'I love you'. But, for those seduced by a grammar of inside/outside the idea that humans have an inner life is what distinguishes them from machines. Vitally, we need to know that others do have this inner life in order to be reassured we have not encountered an automaton. Mercer seeks to provide an explanation for distinguishing between humans and machines in exactly such a way. His position is that emotions are not reducible to the body and so he refutes scientific reductionism. 'Something' more is going on than just the processes that are biologically causing the emotion. Thus, at the level of the individual our inner lives are richer than reductionism claims because we 'experience' our emotions. If the experiential richness of our inner lives were not present, then emotion 'would have a third-person objective ontology and ... one could in principle build a machine capable of guilt'. ${ }^{37}$ To successfully cross the threshold of knowability in such ways and have some confidence in the humanity of others, therefore, fulfils a desire to assure ourselves that we are distinct from machines and therefore, are living in the world with human others and are not alone in the world. ${ }^{38}$

To sum up the first part of my argument so far, a neo-Jamesian grammar of inside/outside accepts, as given, an ontological distinction between the inner and the outer. It has grammatically produced the following pictures: (i) the meaning of an emotion word is the 'object'/phenomenon to which it refers; (ii) emotions refer to inner, ontologically subjective 'objects' of experience; (iii) the only person who can directly know that their emotion is 'genuine' is the person who 'experiences' it; (iv) emotions are private and, because of it, partially hidden; (v) emotions provide the possibility and occasion for scepticism; (vi) we cannot know, with confidence,

\footnotetext{
${ }^{32}$ Crawford, 'The passion of world politics', p. 118.

${ }^{33}$ Mercer, 'Feeling like a state', p. 519.

${ }^{34}$ Ibid.

${ }^{35}$ Hutchison and Bleiker, 'Theorizing emotions in world politics', p. 507.

${ }^{36}$ Stephen Mulhall, 'Picturing the human (body and soul): a reading of Blade Runner', Film and Philosophy, 1 (1994), pp. 87-104 and Pin-Fat, 'Cosmopolitanism and the end of humanity'; Pin-Fat, 'Seeing humanity anew'.

${ }^{37}$ Mercer, 'Feeling like a state', p. 519.

${ }^{38}$ Mulhall, 'Picturing the human (body and soul)'; Pin-Fat, 'Cosmopolitanism and the end of humanity'; Pin-Fat, 'Seeing humanity anew'.
} 
whether an other has the reality of an inner life; and (vii) the desire to cross the threshold of knowability expresses a desire for knowledge in the face of scepticism. In the next two sections, I proceed to argue that these are the very features of what Stanley Cavell calls the 'skeptical recital' and moreover, they express an avoidance of love.

\section{'The avoidance of love,39}

Scepticism is a search for knowledge against a backdrop of, often times, insurmountable epistemological doubt. Stanley Cavell's career was spent examining the desires and effects of scepticism in philosophy as well as his studies of literature and film. ${ }^{40}$ There are several ways in which Cavell has traced and described scepticism's effects that have implications for IR: (1) the annihilation of the other or soul-blindness; ${ }^{41}$ (2) the avoidance of love; ${ }^{42}$ and (3) horror. ${ }^{43}$ In this section I focus on illustrating how the sceptic's, and indeed IR's, grammar of inside/outside is an avoidance of love. I do so by introducing Cavell's reading of Shakespeare's King Lear in order to highlight those aspects that speak to the discipline of International Relations and ultimately, speak to neo-Jamesian contributions to its emotional turn. What is particularly interesting for us is that the king, of course, represents sovereign power. Consequently, reading King Lear's avoidance of love as a form of sovereign, sceptical encounter with the other underscores just how seductive, pervasive, and violent IR's founding grammar of inside/outside can be.

The sceptic's problem of knowledge of other minds - how can I know that the others with whom I am to live in the world exist, that is, are human (others) and not automatons - Kant called 'the scandal of philosophy'. ${ }^{44}$ It may well be a scandal (I fear that it is) but what might it express? For Cavell, the sceptic expresses a desire for knowledge in the face of its absence. Hence, scepticism announces the moment at which knowing is installed and privileged as a way of standing in relation to, and encountering, other people and the world. More to the point, we need to be clear that scepticism is a particular kind of privileged line drawing practice. 'The beginning of skepticism is the insinuation of absence, of a line, or limitation, hence the creation of a want, or desire. ${ }^{45}$ The Wittgensteinian insight is that the line is not innocent. ${ }^{46}$ The line is simply assumed and, more to the point, the acceptance of the assumption has installed the threat of irretrievable outsideness, an uncrossable line, a position from which it is obvious (without argument) that the world is unknowable'. ${ }^{47}$ By reading grammatically we can interrogate the politics and ethics of this line. In my opinion, Cavell enables such a reading by re-presenting the line, the threshold of knowability, in ways that facilitate explicit engagement with the ethical implications of neo-Jamesian theorisations of emotions in IR.

Cavell's great insight is to re-present the sceptic's desire for knowledge (in its assumed absence) as a response to how to live; we might say, he seeks to show us how 'the skeptical recital'

\footnotetext{
${ }^{39}$ Stanley Cavell, Must We Mean What We Say? (Cambridge: Cambridge University Press, 2002), pp. 267-353.

${ }^{40}$ Conant, rightly in my view, insists that readers of Cavell note carefully the differences in his treatment of scepticism of other minds compared to scepticism of the external world. Scepticism of other minds (the existence of others) is what is pertinent to the problem of love. James Conant, 'On Bruns, on Cavell', Critical Inquiry, 17:3 (1991), pp. 616-34.

${ }^{41}$ Stanley Cavell, The Claim of Reason: Wittgenstein, Skepticism, Morality, and Tragedy (New York and Oxford: Oxford University Press, 1999); Pin-Fat, 'Cosmopolitanism and the end of humanity'; Pin-Fat, 'Seeing humanity anew'.

${ }^{42}$ Cavell, Must We Mean What We Say?

${ }^{43}$ Cavell, The Claim of Reason. Also Véronique Pin-Fat, 'Afterword: the horror of love', in Valentina Abenavoli, Anaesthesia (London: Akina Books, 2016). Neither of these is entirely synonymous but they do, unsurprisingly, bear a strong family resemblance.

${ }^{44}$ Kant, cited in Cavell, Philosophy the Day after Tomorrow, p. 133.

${ }^{45}$ Cavell, cited in Conant, 'On Bruns, on Cavell', p. 633.

${ }^{46}$ Conant, 'On Bruns, on Cavell'.

${ }^{47}$ Cavell, cited in Conant, 'On Bruns, on Cavell', p. 633.
} 
is an ethics itself and therefore, presents us with an occasion for self-reflection and a reexamination of our own way of life. ${ }^{48}$ Indeed, he shows us over and over again that scepticism reveals that 'Nothing is more human than the wish to deny one's humanity. ${ }^{49}$ Put differently, 'skepticism concerning other minds is not skepticism but is tragedy'. ${ }^{50}$ Cavell's redescription of scepticism is his way of instigating a Wittgensteinian change of aspect: The change from seeing scepticism as an epistemological problem to seeing it as 'a relation to the world, and to others, and to myself, and to language. ${ }^{51}$ In short, scepticism is an ethics and politics of human encounter. As we shall see below, the evidence for the presence of scepticism in IR is best located through a reading that is focused on grammar; in this case, the sceptical grammar of inside/ outside.

Cavell engaged with Shakespeare philosophically because he read several Shakespearean plays to express the tragedy of the 'skeptical recital'. ${ }^{2}$ His Must We Mean What We Say? has as its final chapter a reading of King Lear entitled 'The Avoidance of Love'. ${ }^{33}$ For Cavell, it is the tragedy of a sceptic (King Lear) and a cautionary tale of how it is that a sceptic stands in relation to the world and others with which it is shared. Ultimately, at least in the case of the king, it is a way of living that shows a fear of revealing and exposing oneself to the other through love. It is a denial of relationality that produces deadly consequences both for the one whose love he disavows and for himself. More to the point perhaps, it is also the cautionary tale of what happens when sovereign power practices an avoidance of love because of being seduced by the grammar of inside/outside.

In Shakespeare's play, King Lear wants to know which of his daughters - Goneril, Cordelia, or Regan - loves him the most such that he will bequeath her the largest share of his kingdom on his abdication. He wants proof, which is to say that he wants grounds upon which to base knowing, that he is loved. One of his daughters, Cordelia, is devoted to him and loves him with all her heart. In the face of sincere love, as felt by Cordelia for her father, King Lear's demand for proof of her love is impossible to meet. The demand insinuates an absence of receipt - a lack of having received Cordelia's love - when, from her point of view, her offering of love is present in full sight and should require no proof. Nevertheless King Lear's sovereign requirement, upon which the division of his kingdom depends, is that a public declaration of love be made. Of course, to satisfy the king's (epistemological) demand is not necessarily a gift of love when a public expression of love need not always be accompanied by genuine sentiment. Indeed, Shakespeare's play pivots on this, for King Lear's other daughters are happy to accede to his demand for their share of his kingdom and yet, love him not. Indeed, their public declarations are the very means by which they deceive the king and pretend to love him. As Neta Crawford noted above, 'it may be difficult to distinguish "genuine" emotions from their instrumental display, ${ }^{54}$

What matters for the grammatical reading here is that the criteria that King Lear has evoked for proof of love (and indeed its measurement) are misplaced. Cavell puts it this way 'to pretend publicly to love, where you do not love, is easy; to pretend to love, where you really do love, is not

\footnotetext{
${ }^{48}$ Cavell calls his own approach to ethics 'moral perfectionism'. Stanley Cavell, Conditions Handsome and Unhandsome: The Constitution of Emersonian Perfectionism (La Salle, IL: University of Chicago Press, 1990).

${ }^{49}$ Cavell, The Claim of Reason, p. 634.

${ }^{50}$ Ibid., pp. xxii-xxiii. In this sense, Cavell's answer to Kant's outrage at scepticism as the 'scandal of philosophy' is to say, 'Here is the scandal of skepticism with respect to the existence of others; I am the scandal.' Stanley Cavell, Cities of Words: Pedagogical Letters on a Register of the Moral Life (Cambridge, MA: Belknap Press of Harvard University Press, 2004), pp. xi, 458,50 .

${ }^{51}$ Stanley Cavell, 'The uncanniness of the ordinary', in 'The Tanner Lectures on Human Values' (delivered at Stanford University, 1986), p. 85, emphasis added.

${ }^{52}$ Cavell does not confine himself to reading King Lear. See also Stanley Cavell, Disowning Knowledge in Seven Plays of Shakespeare (Cambridge and New York: Cambridge University Press, 2003).

${ }^{53}$ Cavell, Must We Mean What We Say?, pp. 267-353.

${ }^{54}$ Crawford, 'The passion of world politics', p. 118.
} 
obviously possible, ${ }^{55}$ As such, after Cordelia's sisters have secured their share of the realm by publicly proclaiming their love for the King in ways that Lear can recognise as satisfying his desire to know, Cordelia is forced to respond to the King's demand of, 'What can you say to draw a third more opulent than your sisters? ${ }^{56}$ Cordelia simply replies, 'Nothing.' And in that moment Cordelia is disinherited and disowned. Cavell tells us that 'Lear is torturing her, claiming her devotion, which she wants to give, but forcing her to help him betray (or not to betray) it, to falsify it publicly. ${ }^{, 57}$

The scenario is not so far removed from an ordinary occurrence of someone you love demanding, 'Tell me that you love me', or 'Prove to me that you love me' in a moment of doubt, neediness, conflict, or maybe insecurity? It's the kind of moment where, for some, it is dificult not to hesitate and possibly refuse to accede to the demand: 'But if I tell you now, it's no proof of my love only proof of my fulfilling your demand.' A case where the means of proof cannot deliver what one wants proved. Perhaps, one gives in and says, 'I love you' to which the reply comes, 'You're only saying that. You don't really mean it!' What kind of proof can one possibly offer in such a situation? Silence perhaps? A refusal to answer even at the risk of the questioner taking the refusal as rejection and proof of the grounds for their doubt? Effectively that is what Cordelia chooses as her response. 'Nothing', she says. But, she carries on loving him anyway.

Cavell's reading of the tragedy highlights the inability of King Lear to 'acknowledge those [he] love[s] on grounds other than knowledge' ${ }^{58}$ The demand for proof, grounded knowledge, creates an avoidance of love; a refusal to accept, recognise, and acknowledge a love that is already there. Tragically, it creates the desire to have one's need to be loved fulfilled by an attachment to a mode of proof that cannot possibly deliver it. King Lear turns away from Cordelia's love and in so doing abjectly fails to recognise his own need for 'love or acknowledgement'.

Basing our encounters with each other on the need to know - a knowledge relation - enables a form of hiding. Being in relation to an other through knowledge illustrates a form of life that has what Davide Sparti calls 'life-withdrawing consequences'. ${ }^{60}$ Why? Because the sceptical recital is premised on a diagnosis of the human condition wherein others cannot be directly known. That means that what, apparently, can be hidden - what can be avoided - is 'one's need of and hence dependency on the other, thus, one's incompleteness and potential vulnerability. ${ }^{61}$ Or at least, one can continue in this sceptical fantasy for as long as one does not acknowledge and express love thereby, making public one's need, vulnerability, and exposure to others. King Lear's inability to acknowledge Cordelia's love 'reflects his fear of confronting himself as a human being. 62

Why should any of this matter to International Relations? In seeking to elaborate the avoidance of love I am pointing to the desires that scepticism expresses. One of these desires is the desire to know - the desire to cross an assumed threshold of knowability in order to encounter an other. The tragedy is not that knowledge is unavailable; such a position simply accepts scepticism and is subject to the critique here. Rather, the tragedy is that the desire, sometimes the demand, for knowledge blinds us to the relationality and vulnerability that is already before us. The sceptical recital is the expression of a distinction between inside and outside behind (or within?) which we can hide. Lear knows that Cordelia loves him but his

\footnotetext{
${ }^{55}$ Cavell, Must We Mean What We Say?, p. 290.

${ }^{56}$ William Shakespeare, The Tragedy of King Lear (Cambridge: Cambridge University Press, 2005), 1.1.80-1.

${ }^{57}$ Cavell, Must We Mean What We Say?, p. 291.

${ }^{58}$ David Schalkwyk, 'Book Review: Stanley Cavell, Disowning Knowledge in Seven Plays by Shakespeare', Early Theatre, 8 (2005), pp. 131-4 (p. 132).

${ }^{59}$ Ibid., p.132.

${ }^{60}$ Davide Sparti, 'Responsiveness as responsibility: Cavell's reading of Wittgenstein and King Lear as a source for an ethics of interpersonal relationships', Philosophy \& Social Criticism, $26: 5$ (2000), pp. 81-107 (p. 91).

${ }^{61}$ Ibid., p. 92.

${ }^{62}$ Ibid., p. 93.
} 
retreat into demanding public proof of it allows him to disavow her love. It constitutes Lear's annihilation of her. ${ }^{63}$ Lear is unable to acknowledge Cordelia's gift of love and in so doing he is unable to acknowledge her as she actually stands in a love relation to and with him. It is a denial of their relationality and along with it their exposure and vulnerability to each other. And, lest we lose the point of Shakespeare's play, this sets off a chain of events that results in Cordelia's actual death and annihilation. This is tragedy enough but it is all the more obvious when we note that in so doing, King Lear has, at the same time, annihilated himself; the sovereign has denied his own humanity by denying his own being-in-relation to and with her as the daughter he loves the most. In the end, that is what kills him as he is broken with grief by Cordelia's death. Perhaps, we are now better able to appreciate what Cavell is evoking when he said, 'Nothing is more human than the wish to deny one's humanity.'

For the purposes of this grammatical reading, I have argued that Cavell has shown us that the (sovereign) desire to know and have proof of emotions can produce forms of encounter that annihilate the self and other in a disavowal of relationality. The desire for proof rests on accepting the possibility of doubting someone's love. This assumes that love, and emotions, are internally hidden and epistemologically inaccessible without public declarations to make them visible and knowable. And yet, of course, such declarations may not provide proof of the very thing that is at stake. To express doubt of this sort is an avoidance of love. Needless to say, reading love this way has ethical and political implications that require further engagement. On which note, does the avoidance of love and its lethal consequences appear in IR's neo-Jamesian emotional turn? Alas, I fear that it does. I turn to substantiating this claim next.

\section{Crossing the threshold of knowability: Collective emotions and conjunctive solutions}

What is analogous to King Lear's demand for proof of love in the emotional turn? In other words, what is the epistemological sovereign demand that signals the presence of the sceptical recital in neo-Jamesian approaches to emotions in IR? Unsurprisingly, it is the demand to meet the 'key challenge in emotions research: to understand how individual emotions can become collective and political'. ${ }^{64}$ Fulfilling such a demand is identified as a requirement in order to fulfil not only the knowability of emotions but to do so in such a way that it is congruent and consistent with social science research. For neo-Jamesians this means, just as King Lear requests, that emotions be publicly declared and accessible. Without being able to traverse the threshold of knowability - move our knowledge of the existence of emotion from inside (individual, private) to their existence outside (collective, public) - emotions research is impossible and/or irrelevant to IR. At worst, the failure to meet the sovereign demand profoundly delegitimises research endeavours such that one is left to 'posit an ethereal existence, which enters the realm of the spiritual'. ${ }^{65}$ If nothing else, and minimally, this grammatical reading hopes to show that this bifurcation - either knowledge of emotions or 'woo-woo' spirituality - does not exhaust legitimate political and ethical interrogations of emotions research in International Relations. On which note, the aim of this section is to provide evidence that neo-Jamesian answers to researching emotions are attempts at refuting scepticism and so, provide further confirmation of the presence of the sceptical recital. Moreover, as I will show in the following section, the attempts to answer the sceptic ultimately provide conditions of possibility for both the avoidance of love and the violent annihilation of the other.

Whenever a distinction is made, for example between inside and outside, it generates a series of problems that require a 'solution'. Thus far, I have shown how the grammatical separation of inside/outside creates a knowledge problem for emotions and the call for a solution in an

\footnotetext{
${ }^{63}$ 'Annihilation of the other' is Cavell's phrase. Cavell, Philosophy the Day after Tomorrow, p. 5.

${ }^{64}$ Hutchison and Bleiker, 'Theorizing emotions in world politics', p. 507.

${ }^{65}$ Mcdermott, 'The body doesn't lie', p. 562.
} 
epistemological register. Grammatically speaking, solutions typically tend to take the form of being able to overcome the limitations that the distinction - or disjuncture - produces in some way or another. I simply call these 'conjunctive solutions'. ${ }^{66}$ In the case of emotions in IR, this section now turns to examining a range of conjunctive solutions that make crossing the threshold of knowability possible through collective emotions. But note, such distinctions and the need to overcome them are grammatical. That is to say, 'the problems arising through a misinterpretation of our forms of language have the character of depth. They are deep disquietudes; their roots are as deep in us as the forms of our language. ${ }^{67}$

In the case of the emotional turn in IR, the grammar of the sceptical recital has produced a problem that seems deep because it misinterprets language to function through word-object relations (a picture theory of meaning). Specifically, the grammar of inside/outside seemingly presents a double difficulty in need of a conjunctive solution(s). On the one hand, there is the difficulty of having public access to 'genuine' emotions that an individual is experiencing. And on the other hand, the level of the individual, apparently, is not what interests scholars of IR. Rather, we are told that what should concern the discipline is how to theorise emotions at the collective, and hence political, level. ${ }^{68}$ In order to show what this may imply for ethics in IR, I want to focus on two specific conjunctive solutions that neo-Jamesians have proposed. The first relies on the knowability of identity (Mercer) and the second, on the knowability of public processes of institutionalisation (Crawford).

\section{Crossing the threshold with identity}

Jonathan Mercer explicitly declares that he is addressing 'skeptics of group emotion' and therefore, there is no ambiguity in his argument being a response to the grammar of the sceptical recital. ${ }^{69}$ His argument is that social emotions are public, collective, and political because they are an 'emergent property' of groups. Identification with a group (that is, identity) is a particular kind of process of social relation that accounts for the emotional phenomenon of 'feeling like a state'. 'Who we are is what we feel', is the slogan. ${ }^{70}$ Thus, identity serves as Mercer's conjunctive solution to successfully crossing the threshold of knowability and moving emotions from inside to outside. What are the features of this crossing?

In Mercer's neo-Jamesian language game, the sceptic's inside/outside grammar has produced the need for several features to be present in order for social emotions, produced by identity, to be knowable. Obviously, social emotions cannot be the same as individual emotions. Grammatically, the inside must not be conflated with the outside nor can the outside collapse into the inside. Hence, for Mercer, individual and social emotions must be sufficiently distinguishable from each other to avoid equivalence. Secondly, social emotions need to be 'real'. ${ }^{11} \mathrm{We}$ must, given the acceptance of the king's demand, overcome the sceptic's doubt about reality. In Mercer's case, it means that the reality (ontology) of social emotions will need to rest on 'social relations' rather than on their 'substances'. ${ }^{72}$ Thirdly, Mercer needs to overcome the problem of embodiment. In his schema, individual emotions causally require a biological body and functioning brain. This is a fundamental part of their interiority. Groups and states do not have a body and/or brain that is causally analogous. For Mercer's conjunctive solution to work then, there must be no necessary relation or dependence on a group body or group brain. However, social emotions must refer to (name) 'something' in order to be meaningful and not nonsense or

\footnotetext{
${ }^{66}$ Pin-Fat, Universality, Ethics and International Relations, pp. 31-8.

${ }^{67}$ Ludwig Wittgenstein, Philosophical Investigations (Oxford: Wiley-Blackwell, 2009), \$111.

${ }^{68} \mathrm{As}$ this article attests, it is by no means obvious that an interest in the 'politics' of emotions requires and necessitates the study of 'collective' emotions.

${ }^{69}$ Mercer, 'Feeling like a state', p. 521.

${ }^{70}$ Ibid., p. 522.

${ }^{71}$ Ibid., p. 521 .

${ }^{72}$ Ibid.
} 
false. Thus, he proposes that social emotions refer to identity. He says, 'Emotion goes with identity, not the body. ${ }^{73}$ Fourthly, then, if identities are required for social emotions then they are a necessary prerequisite. Without identities there can be no social emotions. Such is Mercer's configuration of the specific features of the sceptic/king's sovereign demand that his acceptance of the grammar of inside/outside has produced. Recalling that a grammatical reading is not engaged with the truth or falsity of these grammatically produced problematics, I now want to trace in more detail how Mercer tries to satisfy these demands in order to cross the threshold of knowability and establish that emotions can be collective and enable the traverse from inside to outside.

'Who we are is what we feel.' An example he gives is British citizens feeling patriotic during the London Olympics in 2012. Patriotism, for example, is a social emotion and not reducible to an individual one. How do we know? For Mercer, we can know because there are four features of group/social emotions that distinguish them from individual emotions. ${ }^{74}$ First, the possibility of differentiating the two kinds of emotional experience relies on the observation that 'how one feels as an individual cannot be generalized to how one will feel as a group'. ${ }^{75}$ An important example he gives is emotional responses to state use of torture. As an individual there may be no hierarchy of value to life but a positive/strong social identity 'makes men [sic] more willing (in hypothetical situations) to value in-group lives more than out-group lives' ${ }^{76}$ State emotions can produce a violence that, as an individual who does not strongly identify with the state, might otherwise be absent. Alas, it hasn't taken us long for the annihilation of the other to become visible as a result of the sceptical recital. I will return to this later.

Second, and relatedly, the strength of emotions is different. Group emotion is stronger than individual emotion because 'one experiences it as objectively true and externally driven, rather than as subjective and individually constructed' ${ }^{77}$ The strength comes from the exteriority (the outside) of emotions that is generated by, grammatically speaking, an epistemological status that refutes scepticism. The occasion for individual doubt is overcome when an individual encounters 'objectively true' group emotions. This exterior (outside, public, knowable) aspect of group emotions is what enables the third point of distinction; group members share 'broadly similar emotions. ${ }^{78}$ The implication here is that, unlike individual emotions that cannot be shared because they are private and hidden, group emotions can be. Consequently, the experience of them is non-individual and non-subjective, that is, objective, for Mercer.

Finally, we move to the importance of identity in establishing the difference between group and individual emotions in Mercer's language game. Returning to the example of state use of torture he says, 'Different identities have different implications for experiencing - or not experiencing - emotions such as guilt. ${ }^{, 79}$ An individual who has a strong identification with that state is more likely to justify their use of torture in order to 'restore positive social identity' ${ }^{80}$ In contrast, an individual who is not feeling 'like a state' and/or whose social identity is not threatened would 'probably' see torture as 'obscene'. ${ }^{81}$

For Mercer, the possibility of group emotions understood as above, depends on the presence of two interrelated aspects: (1) an individual's identification with group identities; and (2) the 'experience' of emotions as an 'ideational structure'. Importantly, ideational structures are

\footnotetext{
${ }^{73}$ Ibid.

${ }^{74}$ Mercer uses the terms 'group emotions' and 'social emotions' interchangeably. This is because a group emotion is, by definition, a social emotion in his language game.

${ }^{75}$ Mercer, 'Feeling like a state', p. 524.

${ }^{76}$ Ibid., p. 526.

${ }^{77}$ Ibid.

${ }^{78}$ Ibid., p. 527.

${ }^{79}$ Ibid., p. 528.

${ }^{80}$ Tarrant et al., cited in ibid.

${ }^{81}$ Ibid., p. 528.
} 
'neither identical to, nor wholly autonomous from, the individuals who constitute them'. ${ }^{82}$ And, they can be an 'emergent property' of group emotions and identity. ${ }^{83}$ Mercer does not confine examples of ideational structures to group emotions, but also includes culture and norms. These structures emerge 'from interacting individuals' and constitute the collective, knowable 'properties of a group', including their emotions. ${ }^{84}$

So, in this language game, if 'who we are is what we feel' then how does the individual become emotionally embroiled in the 'we'? Mercer's answer is that personal identity needs to 'switch' to a social identity. ${ }^{85}$ While he notes that individuals can identify with objects like toasters and hi-fis, objects like this do not have emergent properties and therefore, can create neither group identities nor group emotions. ${ }^{86}$ In contradistinction, individuals can identify with groups, such as states, because groups have emergent properties like culture, norms and of course, group emotions.

Vitally, these emergent properties are implicated in the 'mechanisms' that switch individual identity to social identity. For example, Mercer argues that culture regulates feeling and cognition. How culture influences in this way, is partly explained by the 'fact' that 'culture changes the brain's architecture'. ${ }^{87}$ Indeed, different cultural traditions can produce differences in neural activities 'which provides one explanation for why feeling like a group is common'. ${ }^{88}$ But other than culture, Mercer identifies other interactions that can produce feelings of identification with a group. What they share in common is that each 'mechanism' points to an emergent property. These include the intersubjective influence of members of a group upon each other in such a way that creates conformity, esteem, and meaningful identification with the group; ${ }^{89}$ contagion where other people's specific emotions affects other members in the group $;{ }^{90}$ and 'group-level reactions' to events that implicate the group. ${ }^{91}$

In sum then, group emotions exist because individuals identify with groups, such as states. Peoples' practices of conformity and esteem (norms) as well as culture, can all contribute to producing feelings of identification with the group. These feelings of identification are strongest in relation to fellow members of the group - in-group favouritism - and, in some cases, can produce emotions that are stronger than individual ones. While emergent properties are important as conditions of possibility for 'switching' from individual to social identity, it is the oxytocin that is produced that seems more decisive in explaining in-group favouritism at the level of feeling. For example, 'when one feels like a group, oxytocin promotes ethnocentrism'. ${ }^{92}$ Grammatically speaking, the threshold of knowability has been crossed. The sceptic-king's sovereign demand for knowledge has been answered and emotions can be researched in IR. For all the reasons above, groups have emotions without requiring a group body or brain. The apparent interiority of emotions at the individual level is transformed into external, knowable emotions once an individual has a social identity. In short then, social identity is Mercer's response to the 'scandal of philosophy'. If you want to know whether the person before you is truly human - that is, has an inner life of emotions - the only way to know is if they have a group identity. The political and ethical implications of this grammatical outcome are far-reaching but before examining them, there is an alternative neo-Jamesian conjunctive solution to consider.

\footnotetext{
${ }^{82}$ Ibid., p. 521.

${ }^{83}$ Ibid.

${ }^{84}$ Ibid.

${ }^{85}$ Ibid., p. 523.

${ }^{86}$ Ibid., p. 530.

${ }^{87}$ Ibid., p. 523.

${ }^{88}$ Ibid.

${ }^{89}$ Ibid.

${ }^{90}$ Ibid.

${ }^{91}$ Ibid.

${ }^{92}$ Ibid., p. 526.
} 


\section{Crossing the threshold with institutionalisation}

Although different in its specificities, Neta Crawford is also grammatically driven to refuting scepticism with a conjunctive solution in order that emotions be knowable in IR. In her case she offers the processes of institutionalisation as way of crossing the threshold between individual and collective. Institutionalisation overcomes scepticism by transforming the ephemeral nature of emotions into solid, enduring social structures. Crawford underpins her conjunctive solution in a number of ways but, unlike Mercer who stresses ontology, key to her position is the equivalent epistemological status she gives to both emotions and beliefs. As a neo-Jamesian following Damasio she accepts that 'emotions and cognition do not exist in dichotomy or discontinuity'. ${ }^{93}$ As we shall see, this enables her to claim that 'emotions and beliefs structure the organization of knowledge'. ${ }^{94}$ These are outcomes that are publicly visible and recognisable to IR scholars as political phenomena. Given that for Crawford international politics is a form of 'social reasoning' it should not come as a surprise that she is drawn to giving emotions the same powers of production as beliefs. ${ }^{95}$

To illustrate her point Crawford maps the 'pathways for institutionalization' of emotions such as empathy and fear. ${ }^{96}$ These pathways cross the threshold of knowability so that what was once hidden in the inner world of individuals is now visible in the institutionalisation of 'the dominant beliefs and feelings of the group'. ${ }^{97}$ The pathways that Crawford traces are those that link self and other individually ${ }^{98}$ as well as linking collective selves (in-groups) and others (out-groups). ${ }^{99}$ They are institutionalised pathways of possible emotional responses and interactions that a self may have to and with an other and, like most paths, they are not one-way streets. The responses of one can affect the other who in turn may have an emotional response that affects the initial respondent, and so on. This creates 'feedback loops' as well as 'shaping interactions and the environment'. ${ }^{100}$ So, in this language game emotions have institutionalised pathways, but what do they consist of such that it is possible to 'theorize the relation between individual emotions and groups, including states, and an analysis of how emotions are shaped by and shape group identity, culture and institutions'? ${ }^{101}$

The pathways for the institutionalisation of empathy, for example, consist of being able to mark out where one is starting. In this case, the starting place consists of internal emotional processes. ${ }^{102}$ We already know that this is a neo-Jamesian spot on the map. In the case of sophisticated empathetic responses, they 'require that the brain must be intact and experience normal brain development'. ${ }^{103}$ However, individuals interact with their social environment and have 'initial relationships' of belonging to their in-group. They also observe the other, as a member of the out-group, and can respond to their behaviours and emotional responses. This is a feedback loop. At which point, assuming a healthy brain, an empathetic response may occur. Indeed it must if there is to be any chance of institutionalising empathy as a 'route to peace and justice' for example. ${ }^{104}$

\footnotetext{
${ }^{93}$ Crawford, 'Institutionalizing passion in world politics', p. 537.

${ }^{94}$ Ibid., p. 547.

${ }^{95}$ Ibid., p. 537.

${ }^{96}$ Ibid., p. 544.

${ }^{97}$ Ibid., p. 547.

${ }^{98}$ Ibid., p. 544.

${ }^{99}$ Ibid., p. 547.

${ }^{100}$ Ibid., p. 544.

${ }^{101}$ Ibid., p. 537.

${ }^{102}$ Ibid., p. 543.

${ }^{103}$ Ibid., p. 542.

${ }^{104}$ Ibid., p. 544 .
} 
The likelihood of an empathetic response is enhanced or reduced by one's 'imagination of the other'. ${ }^{105}$ The content of the imagined other 'is accomplished by narratives' such as news stories, narratives of the other in history books, conversations over dinner, and in the classroom. ${ }^{106}$ Of course, some stories are more likely than others to trigger an empathetically accomplished imagined other but 'neuroscience ... confirms [that] an active imagination, the ability to put oneself in the position of another, is the key to empathetic understanding'. ${ }^{107}$ Vitally, it seems that for an emotion such as this to stand a chance of becoming institutionalised the brain must be reshaped, thus 'deepening pathways' ${ }^{108}$ Brains are 'shaped and reshaped by experience (neuroplasticity)', that is, the feedback loops identified by Crawford along the pathway to institutionalisation. All being well, an individual's response to the other will be empathy, which produces the "'trust hormone" oxytocin' thereby enabling the promotion of 'empathy, trust and pro-social behaviour'. ${ }^{109}$ There is then, a biological prerequisite to the possibility of institutionalising emotions so that they become outer, observable, knowable phenomena.

In contrast to Mercer then, Crawford's conjunctive solution rejects the possibility of group emotions or feelings. She thinks that 'individuals feel' and not groups. ${ }^{110}$ This is why her map of pathways to the institutionalisation of empathy is, foundationally, a map of individual emotional responses to observed stimuli that may be informed by an imagination enhanced by narratives that, in the end, produce oxytocin. The implication is that institutional change is explicable at the level of the individual.

However, Crawford recognises that individuals do not exist in a social vacuum. They have social relationships as well as emotional relationships. This too is conceived of as a feedback loop wherein 'emotions are socially shared and constructed, deeply related to how we understand the social world and how we interact through our social institutions'. ${ }^{111}$ But also, emotional relationships with in- and out-groups influence social practices and institutions. In this neo-Jamesian language game an organisation's emotions are institutionalised as 'the dominant beliefs and feelings of the group'. ${ }^{112}$ Crawford is arguing that what will be dominant are those feelings which have deepened pathways and which have been 'enhanced ... by social cues, social practices and the arrangement of organisations'. ${ }^{113}$ In other words, dominant feelings are those that have socially reinforced positive feedback loops that deepen the pathways in individual brains. These dominant emotions are knowable.

Accordingly, the threshold of knowability has been crossed and scepticism refuted. Dominant feelings can now be objects of knowledge for IR scholars because they produce public, visible, 'practices and procedures' in social, 'organizational actors' such as government institutions. ${ }^{114}$ Vitally, the signs of dominant feelings are rendered visible by virtue of their transformation into knowledge practices. These knowledge practices include how organisations 'apprehend their environment, structure the acquisition and organization of knowledge, interpret information, routinize decision-making procedures and operations, and formulate responses to challenges'. ${ }^{115}$ Deftly applying Damasio to IR, Crawford is emboldened to say 'Emotions are recognized, reframed and shaped within institutions in the same way as beliefs." ${ }^{\text {,16 }}$ And in that final

\footnotetext{
${ }^{105}$ Ibid., p. 543.

${ }^{106}$ Ibid.

${ }^{107}$ Ibid.

${ }^{108}$ Ibid., p. 544.

${ }^{109}$ Ibid.

${ }^{110}$ Ibid., p. 546, fn. 12 .

${ }^{111}$ Ibid., p. 546.

${ }^{112}$ Ibid., p. 547.

${ }^{113}$ Ibid., p. 544.

${ }^{114}$ Ibid., p. 547.

${ }^{115} \mathrm{Ibid}$.

${ }^{116} \mathrm{Ibid}$.
} 
conjunctive move everything is (seemingly) resolved. Emotions are no longer individual hidden objects that 'we cannot directly know'. ${ }^{117}$ Rather, they remain individual but operate in institutions with visible effects familiar to social scientists such as, decision-making outcomes, operating procedures, evaluations of threat, choices about intelligence gathering, and so on - in short, an institution's 'behavioural routines'. ${ }^{118}$

So far, my argument about the relevance of love to IR has rested on providing evidence of the presence of the sceptical recital - a grammar of inside/outside - and the conjunctive solutions that it generates as attempts to overcome the problem of knowledge of emotions. Having stayed with emotions more generally, not enough has been said about love and the implications of neoJamesianism as an ethics of encounter. I turn to this next to answer Tina Turner's question, 'What's love got to do with it?'

\section{'What's love but a second-hand emotion?' Lethal modes of encounter in International Relations}

Through 'What's Love Got to Do with It?', Tina Turner sings a possible answer. Love may be nothing but 'a second-hand emotion', she tells us. ${ }^{119}$ In this section I want to argue that neoJamesianism is an example of how IR can only recognise love after it has first passed through the hands of satisfying the epistemological criteria of conformity. I fear that if love's second-handedness, as a sovereign demand to conform, remains invisible and unchallenged IR commits itself to avoiding love and a potentially lethal ethics of encounter. A grammatical reading is one way of challenging love's second-handedness by making the familiar (IR's emotional turn) unfamiliar (as an example of IR's avoidance of love).

\section{'I conform therefore, I am': Collective emotions as a picture of humanity ${ }^{120}$}

In what sense does neo-Jamesianism imply that love is nothing but a second-hand emotion? As we have seen, scepticism's grammar of inner vs outer privileges knowledge relations as our way of encountering each other and the world. Its grammar is one that 'forces us to convert a fact of human life (our separateness) in[to] an epistemological difficulty (the impossibility of knowing the other)'. ${ }^{121}$ In this moral imaginary we are left to encounter each other in an epistemological register with all the scepticism (and responses to scepticism) that it brings in its trail. And, of course, it is precisely the idea that we must encounter each other in this way - that we must cross the threshold of knowability in order to love one another - that Shakespeare's King Lear expresses as human tragedy. In this grammatically constituted reality then, love can only be 'a second-hand emotion'; love can only be trusted once it has passed through the hands of satisfying our epistemological criteria. We might say that love's second-handedness derives from accepting the sovereign demand to know. Grammatically speaking, to accept this way of encountering others in the world is to insist that first-hand love for, from and with the other is impossible because we cannot experience/feel another's feelings directly. Such is the price of the sceptical recital's bifurcation of inner and outer. But how might the conjunctive solutions above, as the practice of second-hand emotions, enable a violent denial of the reality of the other? To continue to explore this question grammatically is to offer up a challenge to a denial of our relationality, exposure, and vulnerability to each other. In the final analysis an avoidance of love

\footnotetext{
${ }^{117}$ Ibid., p. 546 , fn. 12.

${ }^{118}$ Ibid., p. 547.

${ }^{119}$ Thanks to Adrian Kerr for pointing out the connection between my argument and this part of Turner's lyrics.

${ }^{120} \mathrm{I}$ am obviously playing with Descartes' famous 'cogito ergo sum'.

${ }^{121}$ Sparti, 'Responsiveness as responsibility', p. 90.
} 
is a disavowal of ethical encounter as a stance towards each other that involves the acknowledgement of the reality of other people. ${ }^{122}$

To be clear, what is at stake in the sceptical recital is nothing less than the reality of the other as human (as opposed to an automaton or animal). Thus, the conjunctive solutions proposed by Mercer and Crawford imply the criteria and conditions under which the other can be known as a human other. These criteria for crossing the threshold of knowability then, are what enable the humanity of the other to be known collectively, publicly, and politically. In this section, I will argue that such conjunctive solutions grammatically enable the annihilation of the other. How does such a terrible, no doubt unintended, consequence arise? I suggest it happens because the grammar of the sceptical recital, the sovereign demand, has led us here.

Controversially, I think both Mercer and Crawford require conformity for the humanity of the other to be knowable. If we were to accept their proposed criteria for the knowability of collective emotions it would imply that those who do not publicly conform are not recognisably human (at best) or simply are not human (at worst). How the sovereign demands of inside/outside can produce such violence as a literal, rather than figurative, annihilation of the other is not hard to evidence: calls to 'exterminate the cockroaches' during the 1993 Rwandan genocide; the killings, beatings, marginalisation, and inequalities that are perpetrated for a 'failure' to conform to heteronormative modes of being in the world; genocides perpetrated because of the 'failure' of others to conform to a national, ethnic, or group identity; and so on, ad nauseum, are all too much to bear as practices of inside/outside. ${ }^{123} \mathrm{I}$ fear that outcomes such as this are the violent curse and tragedy of the sceptical recital that insists that one must have the means of knowing an other for the other to be human and, more to the point, that those means require conformity.

Not for one moment do I wish to suggest that either Mercer or Crawford would condone, endorse or encourage any of the violences I am pointing to. ${ }^{124}$ Frankly, I admit to being extremely hesitant in making the arguments that follow for this reason and yet, this is where the grammatical reading of neo-Jamesianism has led me. It is not the first, nor will it be the last, time that tracing the effects of grammars has produced deadly conclusions. ${ }^{125}$ As itself a way of doing ethics, the grammatical reading offered here illuminates nothing about the nature of collective emotions. Rather, it focuses on rendering visible the ethical implications of IR's investigatory frameworks of emotions as a reiteration of sovereign violence.

In the case of Mercer, his conjunctive solution - identity - implicitly produces conditions of possibility for humanity that insist that for it to be possible to know that human beings have an inner life of emotions they must identify with a group. It requires that individuals emotionally experience the ontology of the world and humanity as divided. He postulates that it is through, and because of, feelings of identification that humanity is divided into in-groups and out-groups. Mercer cites the research of Smith and Mackie to support his claims. There is 'a strong relationship between positive in-group emotions and in-group identification, as well as a relationship between anger at an out-group and in-group identification'. ${ }^{126}$ So, for Mercer, the extent to

\footnotetext{
${ }^{122}$ I owe this formulation of love to Camilla Kronqvist who says that 'love involves the recognition of the reality of other people'. Camilla Kronqvist, 'Our struggles with reality', in Gustafson, Kronqvist, and McEachrane (eds), Emotions and Understanding, p. 203.

${ }^{123}$ Cavell, The Claim of Reason; Pin-Fat, 'Seeing humanity anew'; Judith Butler, Bodies That Matter: On the Discursive Limits of 'Sex' (Abingdon: Routledge, 2011); Veena Das, Life and Words: Violence and the Descent into the Ordinary (Berkeley and Los Angeles: University of California Press, 2007); Anjana Raghavan, Towards Corporeal Cosmopolitanism: Performing Decolonial Solidarities (London: Rowman and Littlefield, 2017); Cynthia Weber, 'Why is there no queer international theory?', European Journal of International Relations, 21:1 (2015), pp. 27-51.

${ }^{124}$ In fact, quite the opposite as Crawford's interest in empathy attests.

${ }^{125}$ The ethical sting in the tail is that if we don't relinquish this seduction [of words naming objects] we will not find what we think we are looking for where we think we will find it, nor how we think we will find it.' Pin-Fat, Universality, Ethics and International Relations, p. 118.

${ }^{126}$ Mercer, 'Feeling like a state', p. 522.
} 
which one may feel more positively towards one's own (in-)group, as well as the angrier one might feel towards others as out-group, influences one's sense of identification. The produced sense of identification that is generated this way, affects the degree to which people will share their group's emotions. And, of course, it is only group emotions that can be appropriately included in IR because their public ontology makes them knowable and hence, researchable. Grammatically then, for Mercer, group emotions are a collective noun. They are the name of and hence, refer to biologically caused individual experiences of emotions that, with greater or lesser intensity, divide humanity into in- and out-groups. Indeed, the potential violence that is enabled by this ontology has not escaped this neo-Jamesian. If we recall, he says 'when one feels like a group, oxytocin promotes ethnocentrism'. ${ }^{127}$

In the case of Crawford, her conjunctive solution - institutionalisation - implies that knowable emotions belong to the dominant (in-)group that have institutionalised them. We saw above that her conjunctive solution to the problem of the privacy of emotions was to propose that knowledge of emotions is possible via their institutionalisation. The institutionalisation of emotions and beliefs are epistemologically available because they 'structure the organization of knowledge'. ${ }^{128}$ Also evoking the ontology of in-groups and out-groups she claims that the emotions that are thus institutionalised are 'the dominant beliefs and feelings of the group'. ${ }^{129}$ Regardless of the complexity she introduces in her attempts to map feedback loops, the outcome is that knowable emotions in IR are accessed via the institutionalisation of dominant emotions. She hopes that empathy, for example, might become institutionalised through activities that produce the "'trust hormone" oxytocin' thereby enabling the promotion of 'empathy, trust and pro-social behaviour'. ${ }^{130}$

For both Mercer and Crawford the grammar of the sceptical recital produces oxytocin - a hormone that may engender trust among in-groups and hostility towards out-groups. Either way, this explanation of collective emotions naturalises the division of humanity into inside (ingroups) and outside (out-groups). The profoundly ethical and political questions of how and what constitutes group identities, which identity dominates, how this is policed, who is excluded, and what the conditions may be for a specific person to be recognised as sharing that identity are absent here. The neo-Jamesian need to name 'objects' that emotions refer to - the picture theory of meaning - has, ironically, removed from sight the relational from International Relations and with it the ethics of encounter that such understandings of emotions express.

By reading grammatically, a concern with the politics and ethics of the sceptical recital can be (re)introduced. As I have been trying to show, the division of humanity has been grammatically produced rather than neuroscientifically discovered. If, as Mercer insists, persons were prevented, unable, or unwilling to self identify as part of a group - that is, conform to its identity - then they would be unknowable, invisible, and therefore, not subjects of interest to International Relations. Such persons' experiences would remain wholly private and hidden and no conjunctive solution (identification with a group) would be available to them to enable knowledge of the reality of their existence. Similarly with Crawford, if an individual has emotions that are not institutionalised, they too are invisible and unknowable. In practice, this is what happens to the marginalised who by definition of being on the margins, do not conform to in-group identities or dominant belief systems that are institutionalised. They are outcasts; whether literally banished from the kingdom like Cordelia in King Lear or more commonly, simply not granted full recognition as persons politically, socially, and ethically.

As I hope I have shown, it is the insistence that emotions cannot be known first hand that produces what Wittgenstein calls a soul-blindness; an inability or unwillingness to take an

\footnotetext{
${ }^{127}$ Ibid., p. 526.

${ }^{128}$ Crawford, 'Institutionalizing passion in world politics', p. 547.

${ }^{129}$ Ibid.

${ }^{130}$ Ibid., p. 544.
} 
attitude towards the reality/existence of others as people who each have, create, and live lives of meaning, resonance, hopes, dreams, desires, disappointments, loves, hates, challenges, relationships, and so on beyond our knowledge of them. Consequently, 'a skeptical process toward other human beings (others like myself, Descartes says) results not in a realization of my ignorance of the existence of the other, but in my denial of that existence, my refusal to acknowledge it, my psychic annihilation of the other'. ${ }^{131}$ Love as a second-hand emotion then, implies a violent mode of encounter that refuses to acknowledge the other as an ensouled human. ${ }^{132}$ The Cavellian insight is that this violence attends neo-Jamesian expressions of a 'wish for the other's non-existence' in IR's emotional turn. ${ }^{133}$

\section{Conclusion: Love as an acknowledgement of the reality of other people}

Wittgenstein tells us 'The aspects of things which are most important to us are hidden because of their simplicity and familiarity. ${ }^{, 134}$ Tracing the presence and effects of grammar enables a different view of what lies before us as hidden in plain sight. In IR, grammatical readings can be especially used to reveal the ethics and politics of the discipline. As such, I have produced a grammatical reading of neo-Jamesian contributions to the emotional turn in order to reveal the disciplinary presence of a lethal ethics of encounter. This ethics of encounter is simply summarised as an avoidance of love. The avoidance of love is constituted and expressed by one of the most familiar foundations in IR - the grammar of inside/outside. My point is that the lack of self-reflection that is witnessed through an assumed acceptance and use of this grammar contributes to IR's inability to trace its own violent effects as 'a lethal set of attempts to deny the existence of the other as essential to one's own'. ${ }^{135}$

In offering a grammatical reading of the emotional turn, I seek (perhaps unsuccessfully) to both enact and reveal the necessity for a Wittgensteinian change of aspect. For scholars of IR, including those of emotions, such a shift can be occasioned by disciplinary self-reflection. Cavell's lifelong focus on 'the skeptical recital' represents a provocation to move from seeing scepticism as an engagement with problems of knowledge (that is, epistemology) to seeing scepticism as the expression of a violent ethics of encounter that enables the denial and annihilation of the other. Or more simply, this change of aspect enables a view of scepticism as enacting an avoidance of love.

By reading grammatically I seek to offer the same provocation for IR; moving away from the production and evaluation of knowledge claims (about emotions, in this case) to investigating what such an epistemology expresses as a relation to the world and to those with whom we share it. Put differently, the change of aspect made possible by reading grammatically enables a focus on love such that a neo-Jamesian treatment of emotions is understood to express an ethics of encounter. By drawing out the politics and ethics of Cavell's view of the sceptical recital in his reading of King Lear, I suggested that what is most relevant to IR is that the pursuit of knowledge is presented as a sovereign demand that must be conformed to in order that the other be politically recognised. For the sovereign to know that he is loved required that what is private and inner (for example, a daughter's love for her father and sovereign) is made public and therewith, knowable. Of course, in the Shakespearean play, this is what his daughters (who do not love him) do. They make public declarations of love. In so doing they are able to inherit their share of kingdom - be politically recognised - because they have conformed to the sovereign's demand. In contrast, and as an act of love, the daughter who truly loves him refuses to 'prove' her love publicly and is banished.

\footnotetext{
${ }^{131}$ Cavell, cited in Das, Life and Words, p. xxiii.

${ }^{132}$ Cavell, The Claim of Reason; Must We Mean What We Say?; Philosophy the Day after Tomorrow; Das, Life and Words; Mulhall, 'Picturing the human (body and soul)'; Pin-Fat, 'Cosmopolitanism and the end of humanity'; Pin-Fat, 'Seeing humanity anew'; David Schalkwyk, 'Cavell, Wittgenstein, Shakespeare, and skepticism: Othello vs. Cymbeline', Modern Philology, 114:3 (2017), pp. 601-29; Wittgenstein, Philosophical Investigations.

${ }^{133}$ Cavell, cited in Das, Life and Words, p. xxiii.

${ }^{134}$ Wittgenstein, Philosophical Investigations, $\$ 129$.

${ }^{135}$ Cavell, Philosophy the Day after Tomorrow, p. 12.
} 
'Obviously' the academic discipline of IR is nothing if not a set of responses to provide knowledge claims about global politics. ${ }^{136}$ So similarly, the sceptic's problem with knowing that the other exists appears in neo-Jamesian contributions to IR's emotional turn. Like King Lear, they express the sovereign demand to know. They insist that for emotions to be relevant to IR we need to 'understand how individual emotions can become collective and political'. ${ }^{137}$ The private must be made public so that a person's existence in the realm of the political ('kingdom') can be legitimately recognised and occupied. A neo-Jamesian epistemology, once read grammatically, can be re-presented as showing the disciplinary acceptance of conforming to the sovereign's demand. In the case of Mercer, answering the demand tacitly implied that only those who identify with a group could be recognised by sovereign power. And, in the case of Crawford, answering the demand implied that only those emotions which have been institutionalised by the dominant group can be knowable and therefore, politically recognised.

Yet, by paying attention to love in IR, we can see how the grammar of inside/outside constitutes a sovereign demand that is doubled. On the one hand, there is the sovereign demand made of IR scholars to make emotions knowable (that is, 'collective and political'). And, on the other, there is also the sovereign demand directed to the other to present their humanity in ways that the sovereign can recognise. They are grammatically one and the same. If we recall, the lesson of the sceptical recital is that our scepticism of others means that we doubt whether the people around us are properly human with inner lives of emotions, thoughts, dreams, etc. The very question of the humanity or 'existence' of others is introduced as being at stake. As such, the doubled space produced by an unquestioned acceptance of a distinction between inside and outside expresses the conditions for a particular mode of encounter. It is a mode that privileges knowledge and political recognition in conformity to the sovereign demand. Of course, this necessarily implies that all forms of subjectivity that are non-conformist are either not politically recognised as properly human, or worse, are unrecognisable. Is it any wonder that the grammar of inside/outside can so quickly express and produce a lethal ethic of encounter when the history of global politics is awash with the violence suffered by those who have failed to conform to a sovereign's demand of political ideology, race, nationality, sexuality, and/or gender? The disciplinary reproduction of a line between inside and outside is therefore, not innocent. As 'a relation to the world, and to others, and to myself, and to language' the sovereign demand is the violent practice of soul-blindness. ${ }^{138}$ It is revealed here as profoundly political and as the expression of an ethics summarised as an avoidance of love.

However, it is possible to proceed, love, and live differently. After all, Cordelia, the daughter who truly loves King Lear, does and I suspect (or is it a hope?) others like her do, too. Cordelia serves to remind us that there is a different way of loving in which we refuse and resist the urge to withdraw from life. This is love hidden in plain sight. Rather than love as a 'second-hand emotion' (that is, in conformity), Cordelia loves first-hand, so to speak. She accepts that 'love involves the recognition of the reality of other people' rather than their denial. ${ }^{139}$ To love in this way is consistent with what Stanley Cavell calls 'acknowledgement'. Acknowledgement is not a form of (epistemological) recognition but rather a practice - a way of standing to the world and others. Acknowledgement is an ethics of encounter and not epistemological because 'The other can present me with no mark or feature on the basis of which I can settle my attitude. I have to acknowledge humanity in the other, and the basis of it seems to lie in me. ${ }^{, 40}$ Understood this way, the humanity of others (and oneself) depends

\footnotetext{
${ }^{136}$ Obviousness, for Wittgenstein, is precisely the moment we would do well to pause for thought. It may be an example of 'the bewitchment of our intelligence by means of language', Wittgenstein, Philosophical Investigations, \$109.

${ }^{137}$ Hutchison and Bleiker, 'Theorizing emotions in world politics', p. 507.

${ }^{138}$ Cavell, 'The uncanniness of the ordinary', p. 85, emphasis added.

${ }^{139}$ Kronqvist, 'Our struggles with reality', p. 203.

${ }^{140}$ Cavell, The Claim of Reason, p. 433.
} 
profoundly upon our relationality - our reciprocal stance towards one another - and therefore, our vulnerability to and with each other. Thus, I prefer to say that love involves the acknowledgement of the reality of other people. A love like this exceeds and cannot be reduced to loving others that only the sovereign can recognise. As a disciplinary practice of IR, acknowledging rather than avoiding love also implies taking responsibility for the risk of one's complicity in the 'annihilation of the other'.

So, what's love got to do with it? Love as the acknowledgement of the reality of other people resists the requirement to reduce love to what can be known and proved. It refuses to limit love to only those persons that sovereign power can recognise as loveable. As such, the grammatical reading offered here serves as an ethical and political reminder that love is much more than just a second-hand emotion.

Acknowledgements. In loving memory of Stanley Cavell (1926-2018). Thank you to the organisers and participants of the British Academy conference 'Vulnerability and the Politics of Care' especially Doerthe Rosenow, Tina Managhan, Judith Butler, Eva Gold, and Thomas Gregory for their engagement with the article. Also, members of the Performance and Politics International Research Centre, Aberystwyth University much improved the first iteration with their generous comments: Jenny Edkins, Adrian Kear, Lydia Cole, Alexandros Koutsoukis, and Alexander Mack. The supremely helpful anonymous reviewers along with Martin Coward, Dominic Marner, and Anjana Raghavan gave of their time and insights to make this much better than it would otherwise have been. I owe more to Róisín Read and Kathryn Starnes than they know.

Véronique Pin-Fat is Senior Lecturer in International Politics at the University of Manchester. She develops grammatical readings to provoke a change of aspect by revealing the ethics and politics of what lies hidden in plain sight. Her current research is on love.

Cite this article: Pin-Fat, V. 2018. 'What's love got to do with it?' Ethics, emotions, and encounter in International Relations. Review of International Studies 45: 181-200. doi:10.1017/S0260210518000426 